\title{
Alcohol Reward, Dopamine Depletion, and GDNF
}

\author{
Charles L. Pickens and Donna J. Calu \\ Intramural Research Program, NIDA/NIH, Baltimore, Maryland 21224 \\ Review of Barak et al.
}

In 1985, Dackis and Gold (1985) suggested that cocaine addiction stems from the depletion of synaptic dopamine in the mesolimbic dopamine reward system, leading to a dysphoric withdrawal state that drives cocaine seeking to restore dopamine to normal, drug-naive levels. They further speculated that decreased basal dopamine levels may be an underlying mechanism of addiction to other drugs of abuse. This hypothesis gained empirical support from work showing that withdrawal from cocaine, morphine, amphetamine, and alcohol all reduce nucleus accumbens (NAc) dopamine levels (Rossetti et al., 1992). However, despite the impact that the dopamine-depletion hypothesis and related opponent process theories (Koob et al., 1989) have had in guiding research and theory in the addiction field, it is still unknown whether NAc dopamine depletion is responsible for drug seeking and relapse. For instance, precipitation of opiate drug withdrawal symptoms decreases NAc dopamine levels without increasing drug seeking (Shaham et al., 1996). Furthermore, manipulations that increase NAc dopamine reinstate drug seeking after extinction, whereas inhibition of NAc dopamine typically inhibits drug seeking (Stewart, 2000).

As with other drugs of abuse, it is currently unclear whether withdrawal-induced

Received Aug. 15, 2011; revised Sept. 6, 2011; accepted Sept. 8, 2011.

This work was supported by the Intramural Research Program of the National Institute on Drug Abuse.

The authors declare no competing financial interests.

Correspondence should be addressed to Charles Pickens, 251 Bayview Boulevard, Baltimore, MD 21224. E-mail: pickensc@mail.nih.gov.

DOI:10.1523/JNEUROSCI.4222-11.2011

Copyright $\odot 2011$ the authors $\quad 0270-6474 / 11 / 3114833-02 \$ 15.00 / 0$ decreases in NAc dopamine play a role in alcohol seeking and taking. This question led to a recent study in The Journal of Neuroscience by Barak et al. (2011), examining the effects of injecting glial cell line-derived neurotrophic factor (GDNF) into the ventral tegmental area (VTA, the cell body region of midbrain dopamine neurons) on dopamine levels in the NAc and on alcohol reward in alcohol-dependent rats. GDNF, a growth factor critical for the survival and function of midbrain dopamine neurons, plays a complex role in opiate and psychostimulant reward and relapse, with evidence for both inhibitory and facilitatory effects on behavior (Ghitza et al., 2010). In the case of alcohol reward, however, studies by Carnicella and Ron (2009) demonstrated a clear inhibitory effect of VTA GDNF injections on alcohol reward. In the paper by Barak et al. (2011), the authors assessed whether VTA GDNF injections reverse alcohol withdrawal-induced dopamine depletion in the NAc and inhibit alcohol reward, as measured by conditioned place preference (CPP) and alcohol self-administration procedures in alcohol-dependent rats.

In Barak et al. (2011), rats were given intermittent $24 \mathrm{~h}$ access to alcohol solutions three times a week for 7 weeks to develop alcohol dependence. Then NAc extracellular dopamine levels and its response to VTA GDNF injections were measured. The authors showed that NAc dopamine levels in alcohol-dependent rats were significantly decreased after $1 \mathrm{~h}$ of withdrawal and remained low 24 h later. VTA GDNF injections (10 $\mu \mathrm{g} /$ side) in 24-h-withdrawn rats restored NAc dopamine to control (normal) levels.
Next, the authors demonstrated that VTA GDNF injections have functional consequences on behavior. Injections of GDNF into VTA 10 min before pairing one chamber of a CPP apparatus with $0.5 \mathrm{~g} / \mathrm{kg}$ alcohol (i.p.) during two conditioning sessions [interspersed with two pairings of saline (i.p.) in a contextually distinct chamber on the opposite side of the apparatus] prevented the development of CPP in alcoholdependent rats. VTA GDNF injections given $10 \mathrm{~min}$ before a CPP test prevented the expression of CPP. Importantly, VTA injections of GDNF alone caused no preference or aversion. Finally, in alcohol-dependent rats trained to press a lever to receive alcohol (2.5-40\%), VTA GDNF injections produced a downward shift in the doseresponse curve. The rats made fewer responses and received fewer alcohol deliveries at each concentration tested on days when the rats received GDNF compared with days in which they received vehicle injections. Such downward shifts in the dose-response curve are usually interpreted as a decrease in the rewarding effect of the drug.

These results have several important implications for our understanding of GDNF's role in alcohol reward. First, these results extend the authors' previous results showing that VTA GDNF decreases alcohol intake and that heterozygous genetic knock-out of the GDNF gene increases rewarding effects of alcohol (Carnicella et al., 2009). The CPP findings extend the previous work with knock-out mice by showing that the role of GDNF in alcohol reward is localized, at least in part, to the VTA. Second, these findings 
demonstrate a role for GDNF both in acquisition and expression of the CPP memory.

Most relevant to the dopamine-depletion hypothesis is the finding that VTA GDNF injections normalized the decreased NAc dopamine levels during alcohol withdrawal and also decreased alcohol reward. This dual effect of GDNF injections provides one plausible explanation for the role of VTA GDNF in decreasing alcohol reward-reversing the dopamine depleted dysphoric state. However, these are correlative findings that are open to alternative interpretations. One such possibility is that GDNF acts in the VTA to decrease the rewarding effects of alcohol in a dopamine-independent manner. In this regard, there is evidence for dopamineindependent reward mechanisms in the VTA (Nader and van der Kooy, 1997; Ikemoto et al., 1998).

Further investigation is necessary to directly test the mechanistic connection between the effect of VTA GDNF injections on reversal of withdrawal-induced dopamine depletion and attenuation of the rewarding effects of alcohol. One such test of the author's hypothesis that dopamine depletion is critical for driving alcohol seeking is to examine whether dopamine depletion (by infusing dopamine agonists into VTA to inhibit dopamine cell firing and release) is sufficient to drive alcohol seeking in nondependent rats. Another informative test of this idea would be to track dopamine levels in alcohol-dependent rats during prolonged withdrawal and to test the effects of VTA GDNF infusions on CPP and alcohol selfadministration during time points in which baseline NAc dopamine has normalized to predependence levels.

Despite the appeal of the dopaminedepletion hypothesis and related negative reinforcement and opponent process theories (Koob et al., 1989), further research is needed to determine whether withdrawalinduced decreases in NAc dopamine play a critical role in the motivation to seek and take alcohol and other abused drugs.

\section{References}

Barak S, Carnicella S, Yowell QV, Ron D (2011) Glial cell line-derived neurotrophic factor reverses alcohol-induced allostasis of the mesolimbic dopaminergic system: implications for alcohol reward and seeking. J Neurosci 31:9885-9894.

Carnicella S, Ron D (2009) GDNF: a potential target to treat addiction. Pharmacol Ther 122:9-18

Carnicella S, Ahmadiantehrani S, Janak PH, Ron D (2009) GDNF is an endogenous negative regulator of ethanol-mediated reward and of ethanol consumption after a period of abstinence. Alcohol Clin Exp Res 33:1012-1024.

Dackis CA, Gold MS (1985) New concepts in cocaine addiction: the dopamine depletion hypothesis. Neurosci Biobehav Rev 9:469477.

Ghitza UE, Zhai H, Wu P, Airavaara M, Shaham Y, Lu L (2010) Role of BDNF and GDNF in drug reward and relapse: a review. Neurosci Biobehav Rev 35:157-171.

Ikemoto S, Murphy JM, McBride WJ (1998) Regional differences within the rat ventral tegmental area for muscimol self-infusions. Pharmacol Biochem Behav 61:87-92.

Koob GF, Stinus L, Le Moal M, Bloom FE (1989) Opponent process theory of motivation: neurobiological evidence from studies of opiate dependence. Neurosci Biobehav Rev 13:135140.

Nader K, van der Kooy D (1997) Deprivation state switches the neurobiological substrates mediating opiate reward in the ventral tegmental area. J Neurosci 17:383-390.

Rossetti ZL, Hmaidan Y, Gessa GL (1992) Marked inhibition of mesolimbic dopamine release: a common feature of ethanol, morphine, cocaine and amphetamine abstinence in rats. Eur J Pharmacol 221:227-234.

Shaham Y, Rajabi H, Stewart J (1996) Relapse to heroin-seeking under opioid maintenance: the effects of opioid withdrawal, heroin priming and stress. J Neurosci 16:1957-1963.

Stewart J (2000) Pathways to relapse: the neurobiology of drug- and stress-induced relapse to drug-taking. J Psychiatry Neurosci 25:125136 . 